\title{
Diagnosis of Clinical Narrow Pelvis by Intranatal Ultrasound
}

\author{
MN Mochalova ${ }^{1}$, ViktorA Mudrov*2 and AA Mudrov ${ }^{3}$ \\ ${ }^{1}$ Head of The Department of Obstetrics and Gynecology, Russia \\ ${ }^{2}$ Department of Obstetrics and Gynecology, Russia \\ ${ }^{3}$ The Medical Faculty, Russia
}

*Corresponding author: Viktor A Mudrov, Department of Obstetrics and Gynecology, the Medical and Dental Faculties, Chita State

Medical Academy, Chita, Russia

\begin{tabular}{|c|c|}
\hline ARTICLE INFO & ABSTRACT \\
\hline Received: 幽 February 26, 2019 & Summary \\
\hline Published: 㓞 March 14, 2019 & ment of labor with a narrow pelvis is one of the most difficult \\
\hline $\begin{array}{l}\text { Citation: MN Mochalova, ViktorA } \\
\text { Mudrov, AA Mudrov. Diagnosis of Clin- } \\
\text { ical Narrow Pelvis by Intranatal Ultra- } \\
\text { sound. Biomed J Sci \& Tech Res 16(1)- } \\
\text { 2019. BJSTR. MS.ID.002780. }\end{array}$ & $\begin{array}{l}\text { sections of practical obstetrics, because narrow pelvis is the main cause of birth } \\
\text { trauma and childhood disability. The aim of the study was to determine significance of } \\
\text { intranatal ultrasound in the diagnosis of clinical narrow pelvis. On the basis of maternity } \\
\text { hospitals of Trans-Baikal Region in the years 2018-2019 was held retrospective and } \\
\text { prospective analysis of } 60 \text { labor histories, which were divided into } 3 \text { equal groups: group } \\
1 \text { - pregnant women with normal sizes of the large pelvis, group } 2 \text { - pregnant women }\end{array}$ \\
\hline $\begin{array}{l}\text { Keywords: Intranatal ultrasound; } \\
\text { Clinical narrow pelvis; Macrosomia; } \\
\text { Fetal-pelvic disproportion; Trauma; } \\
\text { Injuries }\end{array}$ & $\begin{array}{l}\text { with macrosomia, group } 3 \text { - pregnant women with a reduced size of the large pelvis. } \\
\text { The groups are comparable in age, extragenital pathology and parity of labor. Intranatal } \\
\text { ultrasound was performed by a portable high-end ultrasound scanning device MySono } \\
\text { U6 Samsung Medison. The study was conducted by a convex sensor with two approaches: } \\
\text { transabdominal and transvaginal. The presence of clinical narrow pelvis was evaluated } \\
\text { based on assessment of angle labor's progression }\left({ }^{\circ}\right) \text {, degree of head's configuration } \\
\text { in area of swept seam }(\mathrm{mm}) \text {, cross-sectional area of segment of head's insertion }\left(\mathrm{cm}^{2}\right) \\
\text { and ultrasound modification of Vasten symptom. Thus, intranatal ultrasound allows to } \\
\text { determine not only clinical narrow pelvis, but also to predict birth injuries. }\end{array}$ \\
\hline
\end{tabular}

\section{Introduction}

By definition of Kalganova R.I. a clinical narrow pelvis should include all cases of disproportion between fetal head and woman pelvis, regardless of its size. It is recommended to include in this group of obstetric pathology not only childbirths that ended operatively, but also spontaneous births, during which, especially the biomechanism, insertion and configuration of fetal head, indicate the presence of fetal-pelvic disproportion [1]. High rates of birth injury as a result of pelvic fetal-pelvic disproportion determine the relevance of this study.

\section{Materials and Methods}

On the basis of maternity hospitals of Trans-Baikal Region in the years 2018-2019 was held retrospective and prospective analysis of 60 labor histories, which were divided into 3 equal groups: group 1 - pregnant women with normal sizes of the large pelvis, group 2 - pregnant women with macrosomia, group 3 - pregnant women with a reduced size of the large pelvis. The groups are comparable in age, extragenital pathology and parity of labor. Intranatal ultrasound was performed by a portable highend ultrasound scanning device MySono U6 Samsung Medison. The study was conducted by a convex sensor with two approaches: transabdominal and transvaginal. The presence of clinical narrow pelvis was evaluated based on assessment of angle labor's progression $\left({ }^{\circ}\right)$, degree of head's configuration in area of swept seam (mm), cross-sectional area of segment of head's insertion $\left(\mathrm{cm}^{2}\right)$ and ultrasound modification of Vasten symptom. Translabial 
access was used to determine angle of labor progression, degree of head configuration, and cross-sectional area of head insertion segment; transabdominal access was used to determine ultrasound modified Vasten symptom.

Angle of labor progression was defined as the angle between maximum longitudinal size of $t$ pubic symphysis and the line tangent to the most distant part of the fetal head [2]. Degree of head configuration was defined as the distance corresponding to passage of the parietal bones on each other. To determine cross-sectional area of head insertion segment, the ultrasound sensor was placed between the labia majora in the sagittal position, after which the sensor was rotated $90^{\circ}$ into the frontal plane corresponding to the line between the mounds of the ischial bones (Figure 1). Ultrasound modified Vasten symptom was defined as ratio between line of maximum longitudinal size of pubic symphysis and parallel line consisting of a number of points of fetal head presenting (Figure 2). Statistical processing of research results was carried out using IBM SPSS Statistics Version 25.0.

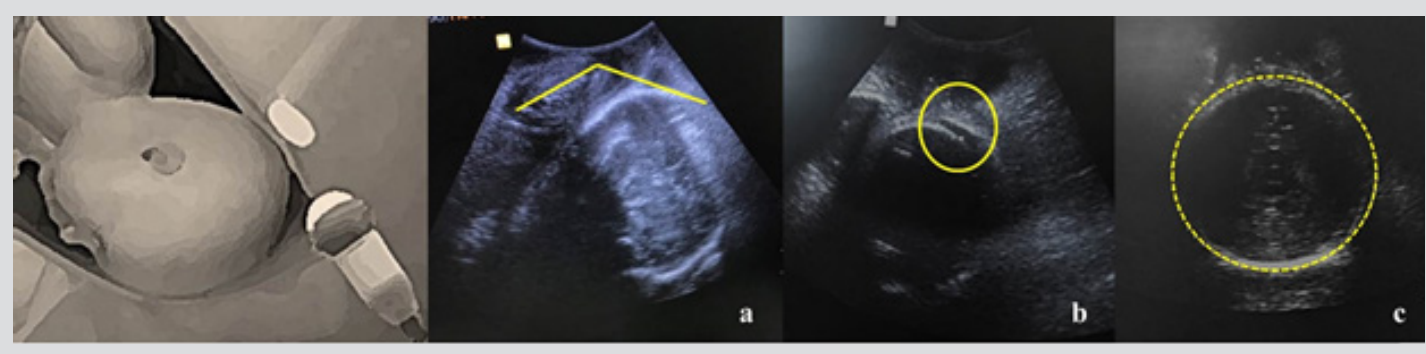

a. angle of labor progression,

b. degree of fetal head configuration

c. cross-sectional area of head insertion segment

Figure 1: Measurement technique by intranatal ultrasound

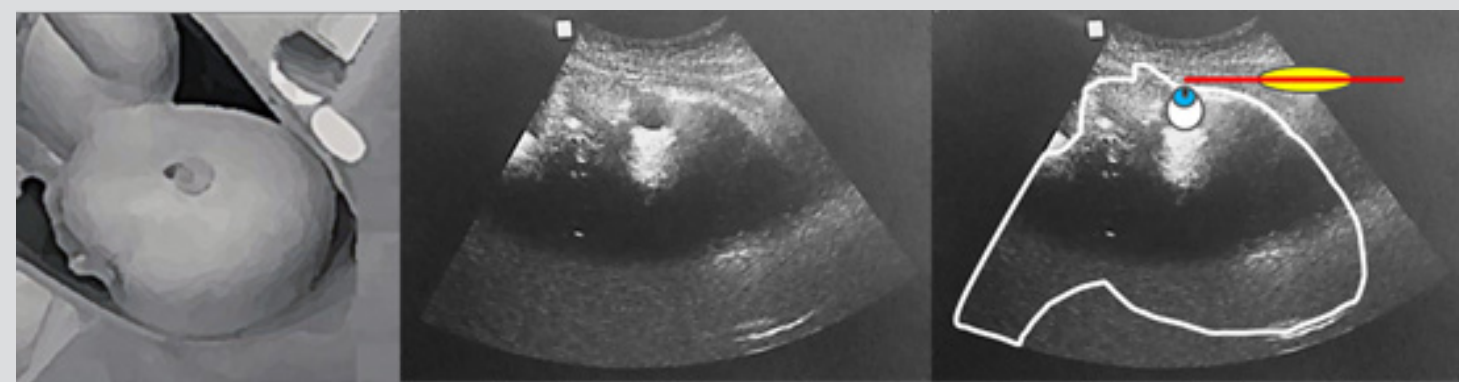

Figure 2: Measurement technique of Vasten symptom by intranatal ultrasound.

\section{Results}

In group 1 , childbirth occurred on a period of 39 weeks \pm 3 days, in group 2 - 38 weeks \pm 4 days, in group 3 - 40 weeks \pm 2 days. The average mass of fetuses at birth in group 1 was $3416 \pm 315$ g, in group $2-2976 \pm 289 \mathrm{~g}(\mathrm{p}<0.05)$, in group $3-4263 \pm 238 \mathrm{~g}$ ( $p<0.05$ ). In group 1, 90\% of births occurred through the natural birth canal $(p<0.05)$. In $10 \%$ there was a deterioration of fetus during the active phase of labor, which, along with discoordination of labor, served as an indication for cesarean section. In group 2 , delivery through the natural genital tract occurred in $60 \%$, in group 3 - in $50 \%$ of cases ( $p>0.05$ ). Angle of labor progression below $120^{\circ}$ with full disclosure of uterine throat was observed in patients with subsequent operative delivery in group 2 in $75 \%$ (6), in group 3 in 100\% (10) of cases ( $<<0.05)$. A reliable relationship between cross-sectional area of head insertion segment and labor outcome was not found, however, this criterion allows us to estimate the progress of labor (by analyzing dynamics of increase in cross-sectional area of head insertion segment). In 30\% of 2 group cases and $10 \%$ of 3 group cases newborns were diagnosed with cephalohematoma. This complication was associated with the degree of head configuration along arrow-shaped seam equal to $16 \mathrm{~mm}$ or more, which indicates the absence of a diagnosis of relative clinical narrow pelvis in these cases $(\mathrm{p}<0.05)$. Ultrasound modified Vasten symptom was positive in 100\% of 2 and 3 group's women, which labors finished by cesarean section due to the clinical narrow pelvis $(\mathrm{p}<0.05)$. In patients whose newborns had cephalohematomas, Vasten's "uniform" symptom was diagnosed by ultrasound in all cases $(\mathrm{p}<0.05)$.

\section{Discussion}

Angle of labor progression, degree of fetal head configuration and ultrasound modified Vasten symptom allow diagnosis of clinical narrow pelvis in pregnant women at high risk in intranatal period, which will optimize delivery tactics and prevent obstetric and perinatal complications. 


\section{Acknowledgement}

There are no Acknowledgements of the authors. There is no conflict of interest. The source of funding is the personal funds of the authors.

\section{References}

1. Kalganova RI (1978) About prenatal care in cases of clinical narrow pelvis. Obstetrics and gynecology 7: 67-70.

\section{ISSN: 2574-1241}

DOI: 10.26717/BJSTR.2019.16.002780

Viktor A Mudrov. Biomed J Sci \& Tech Res

(C) 9 This work is licensed under Creative

Submission Link: https://biomedres.us/submit-manuscript.php
2. Miftahutdinova DK, Teregulova LE, Galimova IR, Gubaidullina SV (2013) Value of angle of progression for assessing the progress of fetal head in the second stage of labor during transperineal ultrasound research. Practical medicine 2(69): 108-111.

$\begin{array}{ll}\text { BIOMEDICAL } & \text { Assets of Publishing with us } \\ \text { RESEARCHES } & \text { - Global archiving of articles } \\ & \text { - Immediate, unrestricted online access } \\ & \text { - Rigorous Peer Review Process } \\ & \text { - Authors Retain Copyrights } \\ \end{array}$

